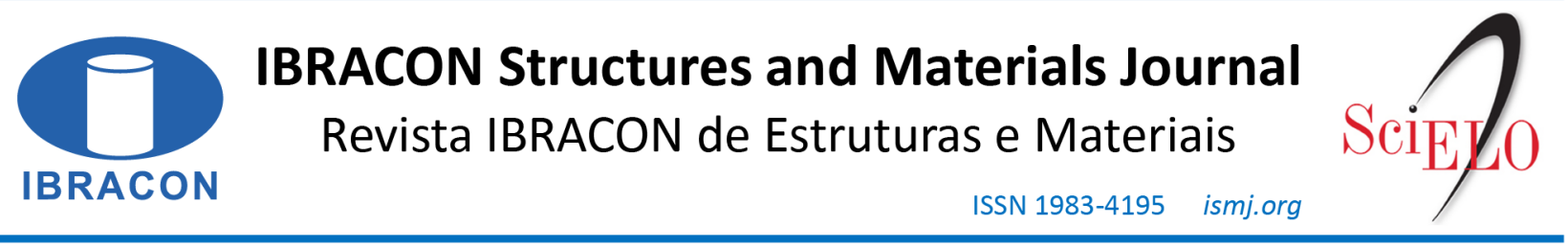

ORIGINAL ARTICLE

\title{
Shear failure in reinforced concrete members without transverse reinforcement: analysis of model error of NBR6118:2014
}

\section{Cisalhamento unidirecional de peças em concreto armado sem armadura transversal: análise do erro de modelo da NBR6118:2014}

\author{
Vinicius Paes de Barros ${ }^{\mathrm{a}, \mathrm{b}}$ \\ André Teófilo Beck ${ }^{\mathrm{c}}$ (D) \\ Túlio Nogueira Bittencout ${ }^{\mathrm{a}}$
}

${ }^{a}$ Universidade de São Paulo - USP, Escola Politécnica, São Paulo, SP, Brasil

bInstituto Federal de Educação, Ciência e Tecnologia de Mato Grosso - IFMT, Cuiabá, MT, Brasil

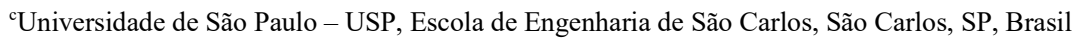

Received 06 February 2020 Accepted 04 June 2020

\begin{abstract}
This article presents an analysis of NBR6118:2014 models used to determine the one-way shear strength in reinforced concrete members without transversal reinforcement. The study compares model predictions with 751 experimental results, taken from the 2015 ACI-DAfStb database and from Quach. Model errors are quantified. Mean values observed are around unity, indicating models with no bias, but coefficients of variation are large. Model error trends are identified with respect to cross-section depth and longitudinal reinforcement rate. In elements with low rate of longitudinal reinforcement and/or large cross-section depths, the normative models provide results with low safety. This shows the need for revision of the normative models. By means of non-linear regression analysis, two correction terms are proposed to consider the longitudinal reinforcement rate and the size effect (decrease in shear strength with increase in section depth). With the proposed corrections, the observed trends are eliminated, and the design equation becomes more accurate with respect to cross-section shear.
\end{abstract}

Keywords: shear, building code, database, model error, size effect.

How to cite: V. P. Barros, A. T. Beck, and T. N. Bittencout, "Shear failure in reinforced concrete members without transverse reinforcement: analysis of model error of NBR6118:2014," Rev. IBRACON Estrut. Mater., vol. 14, no. 1, e14112, 2021, https://doi.org/10.1590/S198341952021000100012

Corresponding author: Vinicius Paes de Barros. E-mail: vinicius.barros@cba.ifmt.edu.br

Financial support: None.

Conflict of interest: Nothing to declare. 


\section{INTRODUCTION}

Designing procedures provided by regulatory codes must be safe, correct in concept, simple to understand, and should not increase design and construction costs unnecessarily. Such procedures are more effective, therefore, when based on relatively simple models instead of complex empirical equations [1].

While in bending strength prediction there are widely accepted models, such as the Euler-Bernoulli hypothesis, in one-way shear of reinforced concrete members, code provisions are usually based on empirical equations calibrated on the basis of available test data [1]-[4]. The reason for this is that, although researchers agree on which mechanisms influence the determination of the shear strength of reinforced concrete members, there is no consensus on whether, or under which circumstances, one mechanism is more important than others [1], [4], [5]. Despite this, the significant amount of research in this topic in the last decades, is evident. Such studies allowed a better understanding of the different mechanisms of shear transfer in concrete, as follows [1], [2]: (a) shear transfer at the crack interface, as a result of the resistance to the sliding of the sections, due to the roughness of cracked concrete and aggregate interlock $\left(\mathrm{V}_{\mathrm{a}}\right)$; (b) dowelling action, related to the shear resistance of the longitudinal reinforcement crossing the crack $\left(\mathrm{V}_{\mathrm{d}}\right)$; (c) arc effect, when the compressed chord inclines towards the support, absorbing part of shear strength and decreasing the traction in the web $\left(\mathrm{V}_{\mathrm{c}}\right)$; (d) residual tensile stresses after cracking the concrete, transferred directly through the cracks $\left(\mathrm{V}_{\mathrm{t}}\right)$. Such mechanisms are shown in Figure 1 and can be seen in more detail in the scientific literature [1], [5].

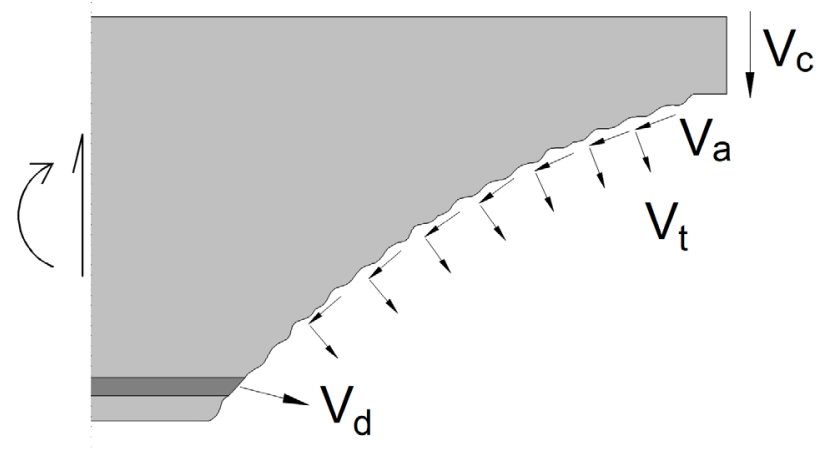

Figure 1. Shear transfer mechanisms in concrete members without transversal reinforcement: aggregate-interlock $\left(\mathrm{V}_{\mathrm{a}}\right)$, dowel action $\left(V_{d}\right)$, arc effect $\left(V_{c}\right)$ and residual tensile strength in cracked concrete $\left(V_{t}\right)$.

Regarding the main parameters that influence the shear strength, we can mention: the tensile strength of concrete, an increase of which leads to increase in shear strength; the relationship between the shear span $(a)$ - defined as the distance from the center of the support to the center of the load causing the shear - and the cross-section effective depth $(d)$ : the higher the $a / d$ ratio, the lower the average shear stress at rupture; the longitudinal reinforcement rate $\left(\rho_{l}\right)$, where higher longitudinal reinforcement rates imply greater shear strength; axial forces, where compression forces increase and tensile forces decrease shear strength; the maximum size of aggregates, which has a direct effect on the shear transfer at the crack interface; and the cross-section effective depth $(d)$, the increase of which causes a reduction in the shear strength (known as size effect $)$. Detailed explanation of these parameters can be found elsewhere [1], [4]-[8].

Due to the difficulty in quantifying the contribution of each shear transfer mechanism, mainly because of the influence of several parameters, different models for shear design have been proposed. As examples: Truss Model; Modified Compression Field Theory (MCFT) [9]; Critical Shear Crack Theory (CSCT) [5] and the Size Effect Law (SEL) [10].

As a result of the presented theories, experimental studies and recent structural accidents, there is a concern in the scientific community for updating the design procedures of regulatory codes, in order to properly consider the mechanisms mentioned, taking into account the various parameters, especially the size effect [11]. As a recent example, the American code ACI 318/2019 [12] updated the one-way shear model for concrete members without transverse reinforcement to address the size effect, and revised the longitudinal reinforcement rate approach, using SEL [10]. Other codes also sought to adopt theoretical models in their texts. Model Code 2010 [13] (for one-way shear design), as well as the Canadian code CSA.A23 2014 [14], use MCFT [9] as the basis for their formulations. The Swiss code [15] and the Model Code 2010 [13] (for punching shear) adopted the CSCT [5]. However, several other codes, such as the 
Brazilian code (NBR 6118/2014) [16] and EUROCODE 2/2004 [17], use purely empirical formulations to determine the contribution of shear transfer mechanisms [18].

\section{OBJETIVE}

In view of the above, it is evident the need to verify the NBR 6118:2014 [16] model for linear members without transverse reinforcement (model for slabs and linear members with $b_{w} \geq 5 d$ ), since this could result in low safety results. For this purpose, this paper proposes to make a comparison between the model of NBR 6118:2014 [16] for one-way shear design of elements without transversal reinforcement and results of shear tests from the ACI-DAfStb database [19] and from Quach [20], evaluating the statistical parameters relevant to the problem. Corrections of the model are also proposed, based on a regression analysis of test results.

\section{THE NBR 6118:2014 MODEL}

For designing linear concrete members without transverse reinforcement, the Brazilian Code, NBR 6118:2014 [16], has a model for slabs and linear elements with $b_{w} \geq 5 d$, these being the only elements that do not have mandatory transverse reinforcement. The resistance contribution of cracked concrete to tensile forces, when there is no axial force, is given by $\tau_{R d 1}$ (Equation 1):

$$
\tau_{R d 1}=\frac{V_{R d l}}{b_{w} d}=\tau_{R d} k\left(1.2+40 \rho_{1}\right)
$$

where $b_{w}$ is the member width, $d$ is the cross-section effective depth and $f_{c t d}$ is the design value of concrete tensile strength. $\tau_{R d}$ is the tensile resistance stress in the concrete (Equation 2).

$$
\tau_{R d}=0.25 f_{c t d}
$$

$\rho_{l}$ is the longitudinal reinforcement rate (Equation 3):

$$
\rho_{I}=\frac{A_{s l}}{b_{w} d} \leq 0.02
$$

and $k$ is a coefficient, with values:

- for elements where $50 \%$ of the longitudinal reinforcement does not reach the support, $k=1$.

- for other cases $k=|1.6-d| \geq 1, d$ in meters.

The Technical Committee CT 301 IBRACON/ABECE [21] makes two recommendations on the use of this model: limit $\tau_{R d}$ to the value corresponding to a characteristic concrete compressive strength of 60MPa, and do not use this equations for elements with cross-section effective depth greater than $600 \mathrm{~mm}$ (suggesting, in this case, the use of EUROCODE 2 formulations).

\section{THE MODEL ERROR}

To determine the resistance of a structural member, we use calculation models, which intend to represent its real behavior, especially close to failure or collapse situations. Due to the enormous complexity of structural behavior, the models have approximations from different origins: arising from physical and geometric linearities, to make models simpler or operational, or even when the nature of the behavior is not completely known [22]. Because of this, it is evident that the models are not $100 \%$ accurate, that is, the predictions of the models differ from results in real structures.

The evaluation of model accuracy, ideally, should be carried out based on the real resistance of the structure or constructed members. However, it is quite complicated to carry out this measurement in loco in a non-destructive way, 
which makes such an approach unfeasible [22]. Thus, it is common to compare the model's prediction with experimental tests, which attempt to replicate a structure or its members in a real-life situation [22].

To make such a comparison, we can use a random variable $\mathcal{E}$, called model error, determined from Equation 4 :

$$
\varepsilon_{i}=\frac{\left(R_{e x p}\right)_{i}}{\left(R_{\text {mod }}\right)_{i}}
$$

where $R_{\text {exp }}$ are the resistances obtained experimentally in the laboratory and $R_{m o d}$ are the resistances obtained from the model.

The main statistics for the random variable $\varepsilon$ are the mean value $\mu_{\varepsilon}$, the variance $\sigma_{\varepsilon}^{2}$ and the coefficient of variation $\delta_{\varepsilon}=\sigma_{\varepsilon} / \mu_{\varepsilon}(\mathrm{COV})$. The statistical sampling error is reduced as the number of tests increases. An ideal model would have unitary mean $\left(\mu_{\varepsilon}=1\right)$ and zero variance $\left(\sigma_{\varepsilon}{ }^{2}=0\right)$; but in practice, a good structural model has a coefficient of variation $\delta_{\varepsilon}$ less than 0.1 [22].

Collins [23] proposed a demerit scale classifying normative procedures for different mean values of $\varepsilon$, as shown in Table 1. In this paper, this demerit scale will be used to classify the model safety, together with variance and coefficient of variation data.

Table 1. Demerit scale for model classification

\begin{tabular}{cc}
\hline$\varepsilon$ & Classification \\
\hline$<0.50$ & Extremely Dangerous \\
\hline $0.50 \mid-0.65$ & Dangerous \\
\hline $0.65 \mid-0.85$ & Low Safety \\
\hline $0.85 \mid-1.30$ & Proper Safety \\
\hline $1.30 \mid-2.00$ & Conservative \\
\hline$>2.00$ & Extremely Conservative \\
\hline
\end{tabular}

\section{METHODOLOGY}

The model error was computed based on results taken from the database of shear tests on reinforced and prestressed concrete members, organized by ACI-DAfstb, in 2015. In this database, 784 tests are on reinforced concrete members without transverse reinforcement, the subject of this article. From those, 34 tests used concretes with strength greater than $90 \mathrm{MPa}$ and were removed, since NBR 6118:2014 [16] is limited to class C90 concrete. In addition, the test performed by Quach [20] was included - a test with a 4 meters high beam - due to the small number of pieces with great depth. Therefore, a total of 751 experiments were used in this paper. In total, 40 flexion tests were performed with uniformly distributed loads, and the remaining 711 with concentrated load, of which 607 flexions at 4 points and 104 flexions at 3 points. Database detailed information can be seen in Reineck et al. [24] and Dunkelberg et al. [19]

For each test in the database, the prediction of shear strength was calculated using the NBR 6118:2014 model (Equation 1). From the results, mean value, variance, standard deviation, coefficient of variation and maximum and minimum values were obtained. The safety coefficients were not included in this study, but the percentage of samples with $\varepsilon<\frac{1}{1.4} \cong 0.71$ was indicated, where 1.4 represents the most usual partial factor for loading combination in the ultimate limit state (ULS).

To address the well-known size effect, the database was divided into effective depth intervals, as done by Bažant and $\mathrm{Yu}$ [7]. In this division, the value of the highest effective depth $d_{f}$ is twice the initial value $d_{i}$, that is, the variation in each interval is equal to the interval's $d_{i}$. In this way, 7 intervals from $d_{i}$ to $d_{f}$ (in millimeters) were obtained: less than 75,75 to 150,150 to 300,300 to 600,600 to 1200,1200 to 2400 and 2400 to 4800 . The data of mean value, variance, standard deviation, coefficient of variation (COV) and maximum and minimum values were generated for each effective depth range. It should also be noted that most of the tests were carried out on small members $(d<500 \mathrm{~mm})$. With this division, a reduction in the variations of the other parameters of influence is also obtained, within each interval $d_{i}$. 
Finally, from the results of the tests, a non-linear regression was performed with the objective of understanding the observed trends.

\section{ANALYSIS OF MODEL ERROR OF NBR6118/2014 FOR SHEAR IN MEMBERS WITHOUT TRANSVERSE REINFORCEMENT}

For the 751 experimental results, the shear resistance prevision of NBR6118:2014 was determined. The calculated results were compared with the experimental ones through the model error $(\varepsilon)$, Equation 5, according to section 4 .

$\varepsilon_{i}=\frac{\left(\tau_{\exp }\right)_{i}}{\left(\tau_{m o d}\right)_{i}}$

$\varepsilon$ values were compared to the Collins demerit scale (Table 1). This analysis includes the mean, median, variance, standard deviation, minimum and maximum values, and coefficient of variation, shown in Table 2. A first analysis shows that the model obtained a mean value slightly higher than the unit, indicating a model with appropriate safety, according to the Collins scale [23]. However, the standard deviation of the sample and, consequently, the coefficient of variation $(\mathrm{COV})$ are large, which indicates that this is not a "good" model, according to Beck [22].

Table 2. Statistics of the model error for the NBR6118 model.

\begin{tabular}{cc}
\hline$\varepsilon$ Statistics & NBR6118 Model \\
\hline Mean Value $(\mu)$ & 1.034 \\
\hline Variance $\left(\sigma^{2}\right)$ & 0.091 \\
\hline Standard Deviation $(\sigma)$ & 0.301 \\
\hline $\operatorname{COV}(\delta)$ & 0.291 \\
\hline Minimum & 0.292 \\
\hline Maximum & 2.835 \\
\hline$\varepsilon<0.71$ & $8.79 \%$ \\
\hline
\end{tabular}

In order to verify how the problem variables influenced the result, graphs were constructed to demonstrate the impact of four variables on the model error results: the effective depth, the longitudinal reinforcement rate, the $a / d$ ratio and concrete strength.

The impact of the effective depth on the model error is shown in Figure 2. Note that most tests are with beams smaller than $600 \mathrm{~mm}$. In addition, there is a tendency for the model error to result in less conservative values with increasing depth.

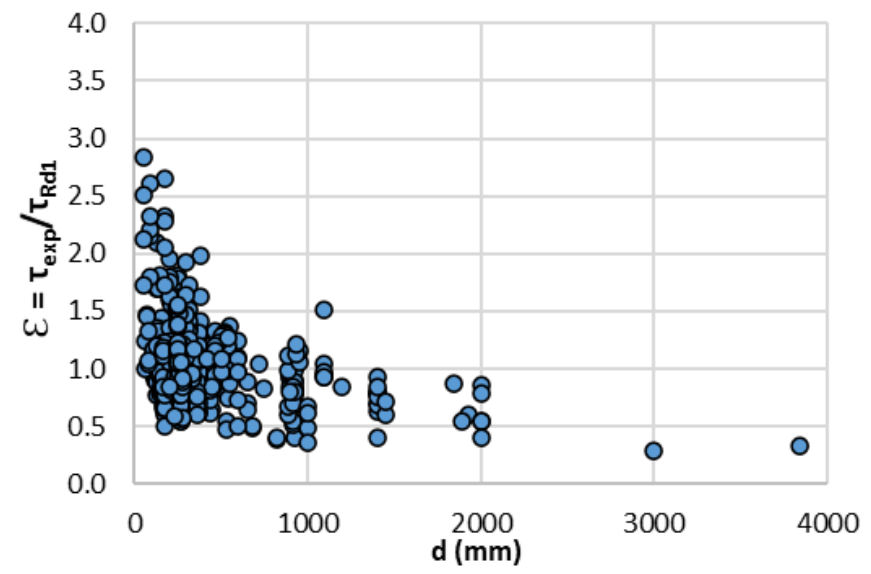

Figure 2. Impact of effective depth on model error 
Figure 3 shows the influence of the longitudinal reinforcement rate on the model error. In this case, the database does not have a large concentration of tests around a specific value; however, it is possible to observe a certain variation depending on the longitudinal reinforcement rate: members with low rate of longitudinal reinforcement tend to have less conservative responses, which indicates that the models may have a tendency in relation to this variable, which was not adequately considered.

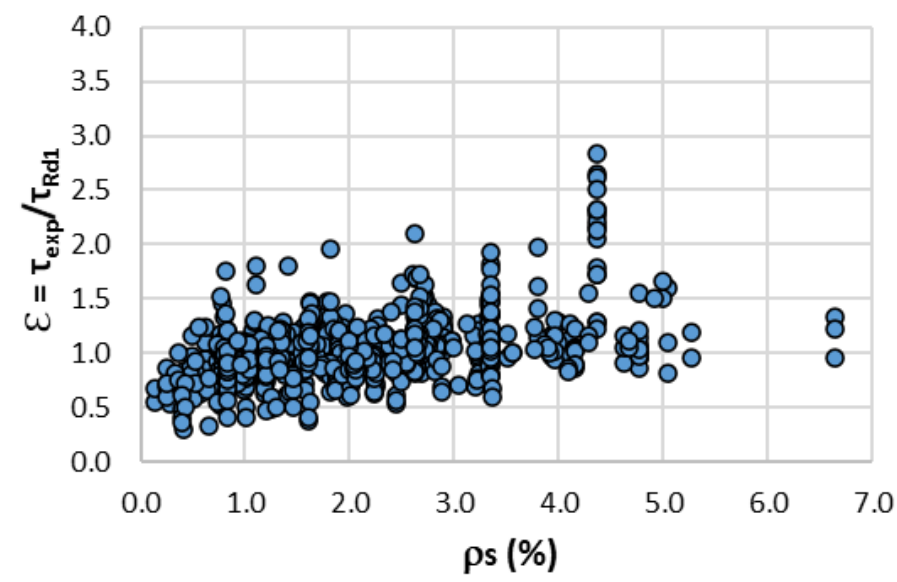

Figure 3. Impact of longitudinal reinforcement rate on model error

Figure 4 shows the influence of $a / d$ ratio and the average compressive strength of concrete. In both cases, there is no visible trend due to these parameters. However, there is a great dispersion for values of $a / d$ ratio around 3 , and average compressive strength around 30MPa.

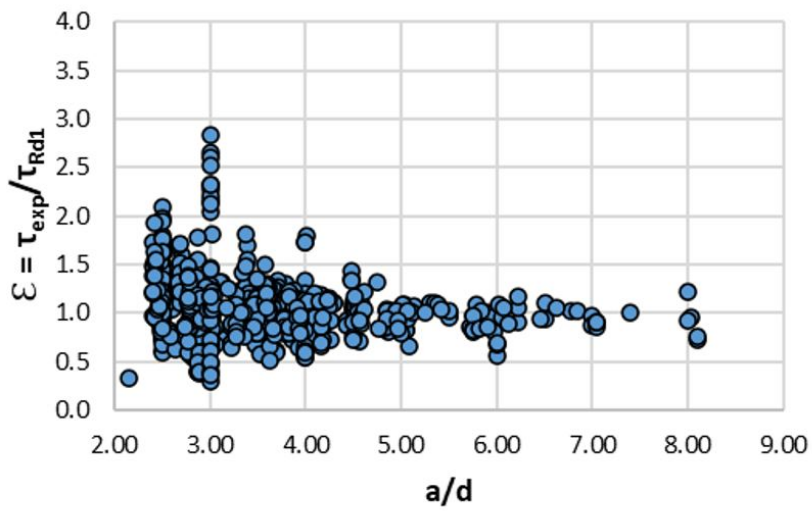

(a)

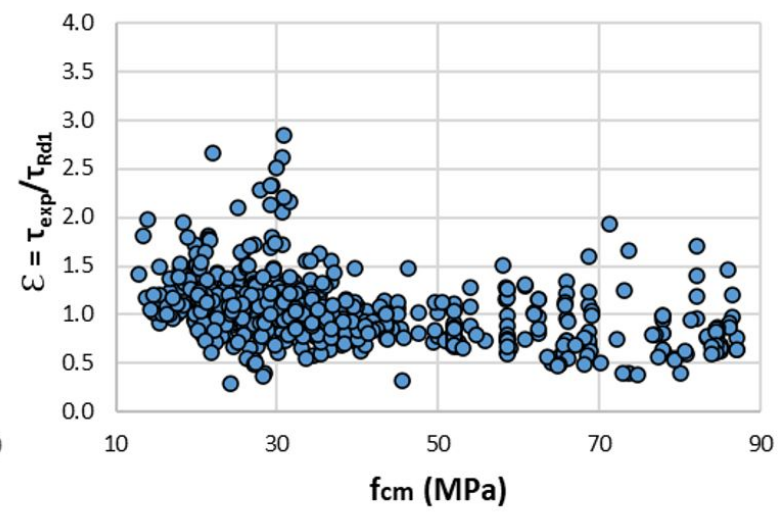

(b)

Figure 4. (a) Impact of a/d ratio on model error, (b) Impact of average compressive concrete strength on model error

Due to the trend observed in the prediction of shear strength and the non-uniform distribution of samples on the effective depth, the methodology of Bažant and Yu [7], presented in section 5, was introduced, dividing the database into 7 different ranges of effective depth. Figure 5 illustrates the percentage distribution of each effective depth range. Note, again, the great concentration of results of small beam heights, mainly between 150 and $300 \mathrm{~mm}$. 


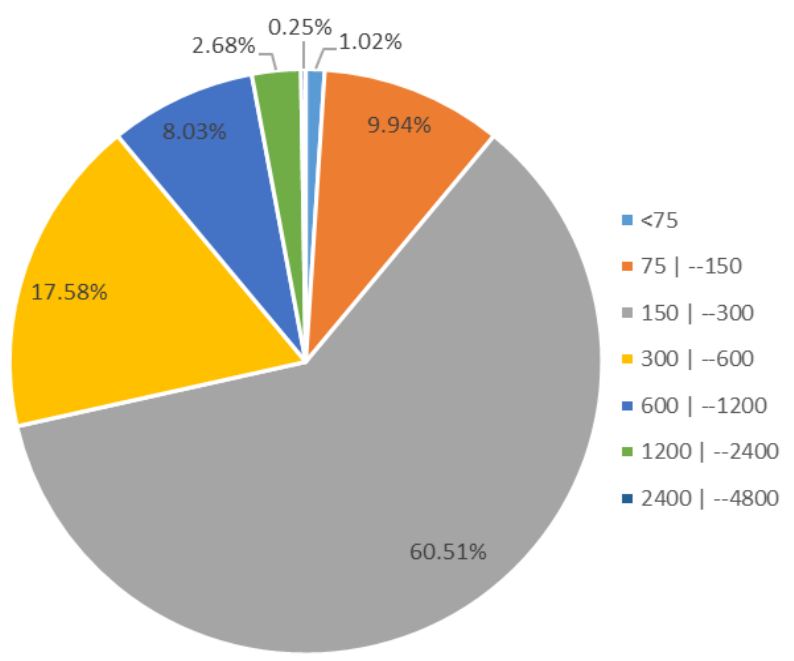

Figure 5. Distribution of the database in relation to the effective depth (in $\mathrm{mm}$ ).

Table 3 presents the results of the statistics of the model error variable by effective depth range. It is observed that the average decreases considerably with the increase of the effective depth.

Table 3. Statistics of model error by effective depth range for NBR6118 model.

\begin{tabular}{cccccccc}
\hline Interval $-\mathbf{d}(\mathbf{m m})$ & $\mathbf{< 7 5}$ & $\mathbf{7 5 - 1 5 0}$ & $\mathbf{1 5 0} \mathbf{- 3 0 0}$ & $\mathbf{3 0 0}-\mathbf{6 0 0}$ & $\mathbf{6 0 0}-\mathbf{1 2 0 0}$ & $\mathbf{1 2 0 0}-\mathbf{2 4 0 0}$ & $\mathbf{2 4 0 0}-\mathbf{4 8 0 0}$ \\
\hline Mean Value $(\mu)$ & 1.797 & 1.215 & 1.042 & 1.006 & 0.823 & 0.696 & 0.309 \\
\hline Variance $\left(\sigma^{2}\right)$ & 0.411 & 0.126 & 0.069 & 0.053 & 0.061 & 0.022 & 0.001 \\
\hline Standard Deviation $(\sigma)$ & 0.641 & 0.356 & 0.263 & 0.231 & 0.248 & 0.150 & 0.024 \\
\hline COV $(\delta)$ & 0.357 & 0.293 & 0.253 & 0.229 & 0.301 & 0.216 & 0.078 \\
\hline Minimum & 0.993 & 0.772 & 0.506 & 0.472 & 0.364 & 0.405 & 0.292 \\
\hline Maximum & 2.835 & 2.610 & 2.656 & 1.982 & 1.509 & 0.921 & 0.326 \\
\hline Number of tests & 8 & 76 & 457 & 132 & 55 & 21 & 2 \\
\hline$\varepsilon<0.71$ & $0.0 \%$ & $0.0 \%$ & $5.9 \%$ & $8.3 \%$ & $34.6 \%$ & $47.6 \%$ & $100.0 \%$ \\
\hline
\end{tabular}

Considering the Collins classification (Table 1), we can conclude that:

- for effective depth less than $75 \mathrm{~mm}$, the mean value greater than 1.3 indicates a "conservative" model, and there are no test results with $\mathcal{E}<0.71$. In this range we obtained the highest mean value, standard deviation and coefficient of variation;

- for effective depths between 75 to $150 \mathrm{~mm}$, the average indicates a model with "appropriate safety" and, despite the high standard deviation, there are no values with $\varepsilon<0.71$;

- for the ranges of effective depth between 150 and $300 \mathrm{~mm}$ and 300 and $600 \mathrm{~mm}$, the mean value is close to unity, therefore classified as "appropriate safety". There are just a few cases of $\varepsilon<0.71(6.45 \%)$, even though these are the groups with the largest number of tests (more than $78 \%$ of the total samples). These are the ranges with the most usual members depths, and it is also where the model predictions best represented the experimental results;

- for effective depths between 600 and $1200 \mathrm{~mm}$, the mean value is less than 0.85 , which indicates a model with "low safety". More than a third of the results showed $\varepsilon<0.71$, which corroborates the classification from the Collins demerit scale;

- for effective depths greater than $1200 \mathrm{~mm}$ and less than $2400 \mathrm{~mm}$, the model has a mean value smaller than 0.70 ("low safety") and $47.7 \%$ of the results with values $\varepsilon<0.71$. In addition, none of the code model's predictions had $\varepsilon>1$, which indicates a strong tendency for the model to overestimate shear strength;

- for the range effective depth greater than $240 \mathrm{~mm}$ and less than $480 \mathrm{~mm}$, the model resulted in values much higher than the experimental results (all samples resulted in $\varepsilon<0.71$ ), in which the mean value indicates an "extremely dangerous" model. 
The effective depth range division shows a strong trend of the normative model to result in less conservative predictions with the increase of effective depth; that is, the size effect is not addressed. However, for members with effective depth smaller than $600 \mathrm{~mm}$, the model presents satisfactory predictions of the experimental results, confirming the observation of IBRACON [21].

\section{PROPOSITION OF A NEW EQUATION FOR NBR6118:2014}

In Section 6 the model error obtained from comparing NBR6118:2014 [16] model for shear design of reinforced concrete members without transverse reinforcement and experimental results of the 2015 ACI-DAfStb shear database [19] and by Quach [20] revealed trends with respect to cross-section depth and longitudinal reinforcement rate. Therefore, two changes to the normative equation (Equation 1) are proposed:

- Change the $k$ coefficient (which is a function of effective depth) so that it addresses the size effect;

- Change the term $\left(1.2+40 \rho_{1}\right)$, which includes the longitudinal reinforcement rate, to improve the representation of this variable, reducing the observed trend.

The $k$ coefficient is replaced by a non-linear expression in the variable $d:\left(c_{1} / d\right)^{c_{2}}$, with $c_{1}$ and $c_{2}$ constants to be determined. The term $\left(1.2+40 \rho_{1}\right)$ is replaced by $c_{3} \rho_{1}^{c_{4}}$, with $c_{3}$ and $c_{4}$ constants to be determined. The proposed expression (Equation 6) considers the formats of the trend graphs (Figures 2 and 3), as well as the formulations of the Canadian and American codes.

$$
\tau_{R I}=\tau_{R}\left(\frac{c_{1}}{d}\right)^{c_{2}} c_{3} \rho_{1}^{c_{4}}
$$

The four constants, $c_{1}$ to $c_{4}$, are determined from non-linear regression with the test data, using the Least Squares Method. In this way, the results are obtained as: $c_{1}=0.6 ; c_{2}=0.4 ; c_{3}=1.35 ; c_{4}=1 / 3$. Equation 7 is the new proposed equation:

$$
\tau_{R I}=1.35\left(\frac{0.6}{d}\right)^{0.4}\left(\rho_{1}\right)^{1 / 3} \tau_{R}
$$

where $d$ is the effective depth, in meters;

$\rho_{l}=\frac{A_{s l}}{b_{w} d}$ is the longitudinal reinforcement rate, in \%;

$\tau_{R}$ is the tensile resistance stress of concrete, obtained from Equation 3, in MPa.

Based on Equation 7, the model error statistics are recalculated, as shown in Table 4. A lower COV and a reduction to $5.6 \%$ of results where the model error is less than 0.71 are observed. The mean value remained close to the previous: 1.092, but COV decreased to 0.235 .

Table 4. Statistics of the model error for the proposed equation.

\begin{tabular}{cc}
\hline$\varepsilon$ Statistics & Proposed Equation \\
\hline Mean Value $(\mu)$ & 1.092 \\
\hline Variance $\left(\sigma^{2}\right)$ & 0.066 \\
\hline Standard Deviation $(\sigma)$ & 0.256 \\
\hline $\operatorname{COV}(\delta)$ & 0.235 \\
\hline Minimum & 0.506 \\
\hline Maximum & 2.084 \\
\hline$\varepsilon<0.71$ & $5.19 \%$ \\
\hline
\end{tabular}


In Figure 6, the model is no longer biased in relation to the effective depth or in relation to the longitudinal reinforcement rate, the two issues pointed out in the current model of NBR6118:2014. It is also verified that the large dispersions for $a / d$ (shear span per effective depth) ratios close to 3 and for the average compressive strength of $30 \mathrm{MPa}$ were reduced. In addition, when observing the values by effective depth range (Table 5), it is possible to observe that the size effect is addressed, since results previously classified as "dangerous" or "extremely dangerous" for large values of $d$, no longer exist.

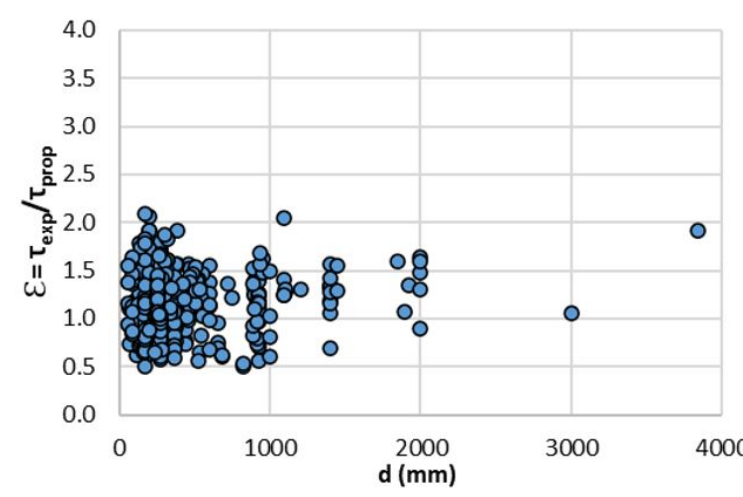

(a)

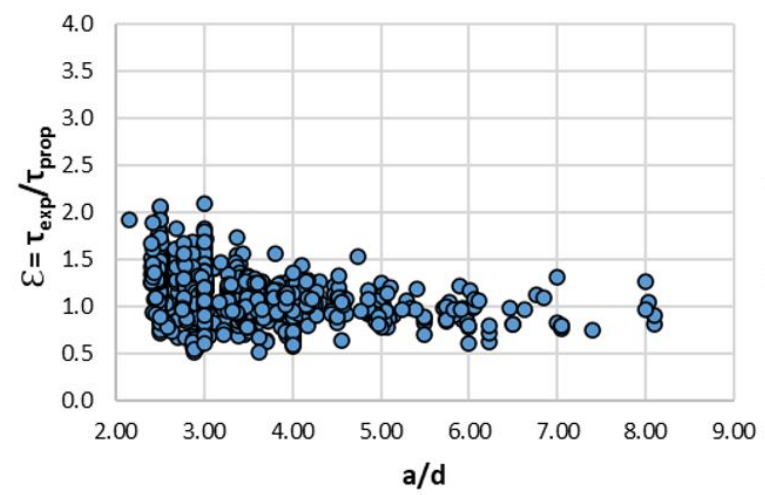

(c)

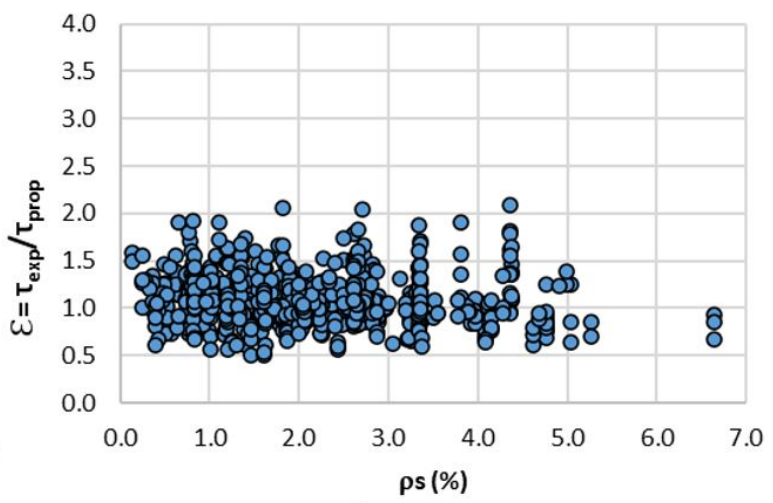

(b)

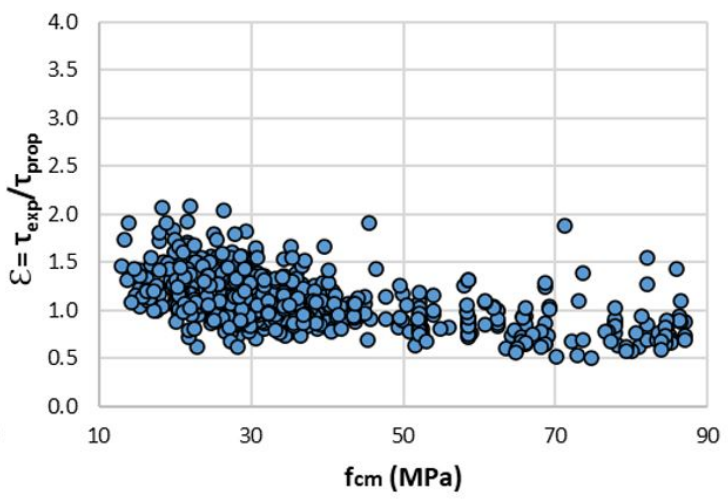

(d)

Figure 6. Impact of (a) effective depth, (b) longitudinal reinforcement rate, (c) a/d ratio and (d) average concrete strength on model error for the proposed equation.

Table 5. Statistics of model error by effective depth range for the proposed equation.

\begin{tabular}{cccccccc}
\hline Interval $-\mathbf{d}(\mathbf{m m})$ & $\mathbf{< 7 5}$ & $\mathbf{7 5 - 1 5 0}$ & $\mathbf{1 5 0}-\mathbf{3 0 0}$ & $\mathbf{3 0 0}-\mathbf{6 0 0}$ & $\mathbf{6 0 0}-\mathbf{1 2 0 0}$ & $\mathbf{1 2 0 0}-\mathbf{2 4 0 0}$ & $\mathbf{2 4 0 0}-\mathbf{4 8 0 0}$ \\
\hline Mean Value $(\mu)$ & 1.112 & 1.015 & 1.068 & 1.160 & 1.131 & 1.305 & 1.485 \\
\hline Variance $\left(\sigma^{2}\right)$ & 0.067 & 0.056 & 0.060 & 0.054 & 0.113 & 0.058 & 0.362 \\
\hline Standard Deviation $(\sigma)$ & 0.259 & 0.237 & 0.244 & 0.233 & 0.335 & 0.240 & 0.602 \\
\hline COV $(\delta)$ & 0.233 & 0.233 & 0.228 & 0.201 & 0.297 & 0.184 & 0.405 \\
\hline Minimum & 0.735 & 0.615 & 0.510 & 0.563 & 0.506 & 0.686 & 1.060 \\
\hline Maximum & 1.548 & 1.785 & 2.084 & 1.911 & 2.042 & 1.634 & 1.911 \\
\hline Number of tests & 8 & 76 & 457 & 132 & 55 & 21 & 2 \\
\hline$\varepsilon<0.71$ & $0.0 \%$ & $2.6 \%$ & $5.7 \%$ & $3.0 \%$ & $14.5 \%$ & $4.7 \%$ & $0.0 \%$ \\
\hline
\end{tabular}

\section{CONCLUSIONS}

The scientific community does not fully understand all the mechanisms and parameters that govern the problem of shear strength on reinforced concrete members, which incurs in many design codes using empirical equations in their provisions, including the Brazilian code (NBR 6118:2014). Recent experimental results have shown, however, that 
those models could provide unsafe design. To verify the model's safety, this paper presented a comparison between model predictions of NBR6118:2014 [16] for one-way shear strength of reinforced concrete members without transversal reinforcement and experimental results compiled from the ACI-DAfStb database [19] and Quach [20], through the analysis of model error variable. From this study, it was concluded that:

a) The current NBR6118:2014 model does not address the size effect; it shows considerable reduction in model error mean, with the increase in effective depth, especially for members with depth greater than $600 \mathrm{~mm}$. In addition, it is biased in relation to the longitudinal reinforcement rate, whose decrease implies in less conservative results (Figures 2 and 3);

b) For values of effective depth between $75 \mathrm{~mm}$ and $600 \mathrm{~mm}$, the model of NBR 6118:2014 gives satisfactory predictions. For effective depths greater than $1200 \mathrm{~mm}$, the predictions are classified as "dangerous" or "extremely dangerous", according to the Collins demerit scale (Table 1);

By means of non-linear regression analysis, this paper proposed an amendment for the NBR6118:2014 model. Results shown that the new equation is not biased with respect to the effective depth or longitudinal reinforcement rate. Mean values are still close to unity, but the coefficient of variation was reduced, from 0.291 to 0.235 , which indicates an improvement in the model. Specimens with $\varepsilon<0.71$ were diminished to $5.19 \%$ of total, pointing to a safer model. Size effect is addressed in the new formulation, a fact observed by safer results for large-scaled specimens. Large dispersions observed for $a / d$ ratio close to 2 and average compressive strength close to $30 \mathrm{MPa}$ were also reduced.

\section{REFERENCES}

[1], ASCE ACI Committee 445, "Recent approaches to shear design of structural concrete," J. Struct. Eng., vol. 124, no. 12, pp. 13751417, Dec 1998, http://dx.doi.org/10.1061/(ASCE)0733-9445(1998)124:12(1375).

[2] F. Cavagnis, M. Fernández Ruiz, and A. Muttoni, "An analysis of the shear-transfer actions in reinforced concrete members without transverse reinforcement based on refined experimental measurements," Struct. Concr., vol. 19, no. 1, pp. 49-64, Nov 2018, http://dx.doi.org/10.1002/suco.201700145.

[3] F. Cavagnis, M. F. Ruiz, and A. Muttoni, "Shear failures in reinforced concrete members without transverse reinforcement: an analysis of the critical shear crack development on the basis of test results," Eng. Struct., vol. 103, pp. 157-173, 2015, http://dx.doi.org/10.1016/j.engstruct.2015.09.015.

[4] P. Huber, T. Huber, and J. Kollegger, "Investigation of the shear behavior of RC beams on the basis of measured crack kinematics," Eng. Struct., vol. 113, pp. 41-58, Apr 2016, http://dx.doi.org/10.1016/j.engstruct.2016.01.025.

[5] A. Muttoni and M. Fernández Ruiz, "From experimental evidence to mechanical modeling and design expressions: the critical shear crack theory for shear design," Struct. Concr., vol. 20, no. 4, pp. 1464-1480, Jun 2019, http://dx.doi.org/10.1002/suco.201900193.

[6] Z. P. Bažant and J. Kim, "Size effect in shear failure of longitudinally reinforced beams," ACI J., vol. 81, no. 5, pp. 456-468, 1984.

[7] Z. P. Bažant and Q. Yu, "Minimizing statistical bias to identify size effect from beam shear database," ACI Struct. J., vol. 105, no. 6, pp. 685-691, Oct 2008.

[8] D. A. Kuchma, S. Wei, D. H. Sanders, A. Belarbi, and L. C. Novak, "Development of the one-way shear design provisions of ACI319 for reinforced concrete," ACI Struct. J., vol. 116, no. 4, pp. 285-295, Jul 2019, http://dx.doi.org/10.14359/51716739.

[9] M. P. Collins and D. Mitchell, Prestressed Concrete Basics, 1st ed. Ottawa: Canadian Prestressed Concrete Institute, 1987.

[10] Z. P. Bažant, "Size effect in blunt fracture: concrete, rock, metal," J. Eng. Mech., vol. 110, no. 4, pp. 518-535, Apr 1984, http://dx.doi.org/10.1061/(ASCE)0733-9399(1984)110:4(518).

[11] Q. Yu, J. Le, M. H. Hubler, R. Wendner, G. Cusatis, and Z. P. Bažant, "Comparison of main models for size effect on shear strength of reinforced and prestressed concrete beams," Struct. Concr., vol. 17, no. 5, pp. 778-789, Dec 2016, http://dx.doi.org/10.1002/suco.201500126.

[12] American Concrete Institute, Building Code Requirements for Structural Concrete, ACI 318, 2019.

[13] Fédération Internationale du Béton, fib Model Code for Concrete Structures 2010, MC2010, 2013.

[14] Canadian Standards Association, Design of Concrete Structures, A23.3, 2014.

[15] Swiss Society of Engineers and Architects, SIA Code 262 for Concrete Structures, SIA 262, 2003.

[16] Associação Brasileira de Normas Técnicas. Projeto de Estruturas de Concreto - Procedimento, NBR 6118, 2014.

[17] European Standard, Eurocode 2 - Design of Concrete Structure - General rules and rules for buildings, EN 1992-1-1, 2004.

[18] A. Dönmez and Z. P. Bažant, "Critique of critical shear crack theory for fib Model Code articles on shear strength and size effect of reinforced concrete beams," Struct. Concr., vol. 20, no. 4, pp. 1451-1463, May 2019, http://dx.doi.org/10.1002/suco.201800315. 
[19] D. Dunkelberg, L. H. Sneed, K. Zilch, and K. Reineck, "The 2015 ACI-DAfStb database of shear tests on slender prestressed concrete beams without stirrups - overview and evaluation of current design approaches," Struct. Concr., vol. 19, no. 6, pp. 17401759, Mar 2018, http://dx.doi.org/10.1002/suco.201700216.

[20] P. T. Quach, "Understanding and safely predicting the shear response of large-scale reinforced concrete structures,” M.S. thesis, Dept. Civ. Eng., Univ. Toronto, Toronto, 2016.

[21] Instituto Brasileiro do Concreto, ABNT NBR 6118:2014 - Comentários e Exemplos de Aplicação, 1st ed. São Paulo: Ibracon, 2015.

[22] A. T. Beck, Confiabilidade e Segurança das Estruturas, 1st ed. Rio de Janeiro: Elsevier, 2019.

[23] M. P. Collins, Evaluation of Shear Design Procedures for Concrete Structures. Canada: CSA Technical Committee on Reinforced Concrete Design, 2001, pp. 29-37.

[24] K. Reineck, E. C. Bentz, B. Fitik, D. A. Kuchma, and O. Bayrak, "ACI-DAfStb database of shear tests on slender reinforced concrete beams without stirrups," ACI Struct. J., vol. 110, pp. 867-876, Sep 2013.

Author contributions: VPB: conceptualization, formal analysis, methodology, writing; A.T.B: writing, proofreading, supervision; TNB: data curation, supervision, proofreading.

Editors: Sérgio Hampshire de Carvalho Santos, José Luiz Antunes de Oliveira e Sousa, Guilherme Aris Parsekian. 